\title{
Exposure to cobalt chromium dust and lung disorders in dental technicians
}

\author{
Anders I Seldén, Bodil Persson, Sten I Bornberger-Dankvardt, Lars E Winström, \\ Lennart S Bodin
}

\begin{abstract}
Background - Dental technician's pneumoconiosis is a dust-induced fibrotic lung disease of fairly recent origin. This study was carried out to estimate its occurrence in Sweden.

Methods - Thirty seven dental technicians in central and south eastern Sweden with at least five years of exposure to dust from cobalt chromium molybdenum (CoCrMo) alloys, identified by postal survey, agreed to undergo chest radiography and assessment of lung function and exposure to inorganic dust.

Results - Six subjects (16\%; $95 \%$ confidence interval $6 \%$ to $23 \%$ ) showed radiological evidence of dental technician's pneumoconiosis. The lung function of the study group was reduced compared with historical reference material. With local exhaust ventilation dust levels were generally low, whereas in dental laboratories without such equipment high levels of dust, particularly cobalt, were found.

Conclusions - Pneumoconiosis may result from exposure to inorganic dust in the manufacturing of CoCrMo-based dental constructions. It is possible to reduce this hazard substantially by local exhaust ventilation.
\end{abstract}

(Thorax 1995;50:769-772)

Keywords: dental technicians, dust exposure, lung function, occupational hygiene, pneumoconiosis.

Sporadic cases of silicosis among dental technicians have been reported since $1939 .{ }^{1-6}$ More recently a new type of dust-induced fibrotic lung disease called dental technician's pneumoconiosis has been found among professionals involved in the making of metal framed removable partial dentures, usually based on various cobalt chromium molybdenum (CoCrMo) alloys. ${ }^{7-11}$ However, aetiological agents have been difficult to identify since the dust exposure in dental laboratories is quite complex. ${ }^{12-14}$

High levels of cobalt in dust samples from the breathing zone of dental technicians working with CoCrMo alloys were found in a previous study and urine from exposed subjects was found to contain increased levels of cobalt. ${ }^{15}$ Later an index case of dental technician's pneumoconiosis appeared in Sweden which stimulated the present cross sectional study aimed at investigating its occurrence in Sweden.

\section{Methods}

MEDICAL SURVEY

A questionnaire asking for the names of dental technicians who had worked with CoCrMo alloys for at least five years was mailed to all 172 dental laboratories in a defined region of central and south eastern Sweden. The catchment area has approximately two million inhabitants comprising almost $25 \%$ of the national population.

Identified subjects received standardised and self-administered questionnaires ${ }^{16}$ surveying their present and previous health, respiratory symptoms, and smoking habits. Also enclosed was an ad hoc one page questionnaire regarding exposure to occupational dust. At a subsequent workplace visit by an environmental nurse the questionnaires were checked and completed, if necessary.

Lung function tests were carried out at the dental laboratories with a transportable spirometer (Compact, Vitalograph, Buckingham, UK). The instrument was calibrated at each location. The best of at least two manoeuvres for the vital capacity (VC) and the forced expiratory volume in one second $\left(\mathrm{FEV}_{1}\right)$, respectively, were recorded at body temperature and pressure saturated with water vapour. Predicted lung function values were calculated from Swedish reference material ${ }^{17}$ taking sex, age, and height into account.

A routine chest radiograph was performed at the nearest department of radiology, from which a radiograph from an age ( \pm five years) and sex matched reference subject was also requested. The radiographs were coded and read independently by two senior physicians (one radiologist, one lung specialist) and the findings were classified according to the International Labour Office (ILO) system for radiological diagnosis of pneumoconioses. ${ }^{18}$ One eligible study subject refused to participate in the radiological examination and for another subject the radiograph (normal at primary reading) could not be retrieved; thus, radiographs from 35 exposed and 21 reference subjects were available for analysis.

The survey was approved by the medical research ethics committees of the two major hospitals involved.

\section{ASSESSMENT OF EXPOSURE}

Data sheets were obtained from producers or local suppliers of potentially dust emitting materials involved in the current manufacturing process. Dust measurements were carried out for those dental technicians who had a mini- 
Table 1 Study group characteristics $(n=37)$

\begin{tabular}{llc}
\hline Variable & Mean & Range \\
\hline Age (years) & $43 \cdot 0$ & $24-64$ \\
Years in mechanical dentistry & 26.0 & $5-46$ \\
Hours/week & $43 \cdot 8$ & $20-73$ \\
Years of work with CoCrMo & $18 \cdot 5$ & $5-36$ \\
Hours/week & $21 \cdot 6$ & $0 \cdot 5-40$ \\
\hline
\end{tabular}

mum weekly working time with CoCrMo alloys of 20 hours. In eight laboratories (out of 24) a total of 10 subjects met this criterion. Full shift air samples were collected and the dust levels were compared with the Swedish occupational exposure limit values for a full working day in effect at the time. ${ }^{19}$

Total dust was analysed gravimetrically while crystalline quartz, cristobalite, tridymite, and silicon carbide were determined by $x$ ray diffraction. Cobalt, chromium, molybdenum, and aluminium were analysed with $x$ ray fluorescence.

\section{STATISTICAL ANALYSIS}

Spirometric findings were analysed by the Student's $t$ test for paired differences (observed minus expected values) and $95 \%$ confidence intervals $(95 \% \mathrm{CI})$ for the mean difference. To examine simultaneously the impact of exposure and smoking multiple regression analyses were performed. The differences between observed and expected values were regressed on exposure (three classes from lowest to highest) and smoking (three classes). For the radiographs the level of interobserver agreement beyond chance was calculated as Cohen's kappa. ${ }^{20}$

\section{Results}

MEDICAL SURVEY

Responses were received from 153 laboratories. Among the non-responders 11 were considered to be genuine and in eight cases the ques- tionnaires were returned because of incorrect addresses. The response rate to the questionnaire from the laboratories was therefore $93 \%$, and from 24 laboratories positive responses were received with names of 44 individuals who tentatively fulfilled the inclusion criteria. However, after checking the exposure history with the appointed technicians and their employers only 37 subjects (34 men) were included in the study (table 1 ).

The lung function of the dental technicians was significantly lower than expected for both $\mathrm{VC}$ and $\mathrm{FEV}_{1}$ with a mean difference of observed to predicted values of approximately -0.31 (table 2 ). The reduction in lung function was more pronounced in smokers than in nonsmokers and ex-smokers.

A dose-response relation between exposure to CoCrMo dust in hours per week and reductions of both VC and $\mathrm{FEV}_{1}$ was found (table 3). The relation also appeared when self estimated levels of dust exposure were taken into account. However, no such dose-response effects were noticed for total numbers of years of exposure to CoCrMo dust (data not shown). Similar findings were obtained when lung function was regressed with dust exposure and smoking.

There was an excellent overall agreement between the readers of the chest radiographs (Cohen's kappa $=0.78$; table 4 ) who both found a small opacity profusion of ILO category 1 or higher (read as $\geqslant 1 / 0$ ) in five exposed subjects. However, the readers disagreed in their classification of two exposed subjects, yielding a total of six radiologically positive cases. Both readers assessed all radiographs from the reference subjects as normal. The lung function of the six cases with radiological evidence of pneumoconiosis was not significantly different from the rest of the study group.

Table 2 Mean (SD) lung function (in litres) by smoking habits in dental technicians exposed to CoCrMo dust

\begin{tabular}{llllll}
\hline & No. & Observed & Predicted & Mean difference (95\% CI) & $p$ value \\
\hline Vital capacity & & & & & \\
$\quad$ All & 37 & $4.92(0.79)$ & $5.26(0.56)$ & $-0.34(-0.54$ to -0.14$)$ & $<0.01$ \\
Smokers & 12 & $4.52(0.69)$ & $5.01(0.38)$ & $-0.48(-0.85$ to -0.12$)$ & $<0.05$ \\
Ex-smokers & 13 & $5.06(0.89)$ & $5.36(0.62)$ & $-0.30(-0.75$ to 0.14$)$ & $>0.05$ \\
$\quad$ Non-smokers & 12 & $5.17(0.68)$ & $5.40(0.60)$ & $-0.23(-0.53$ to 0.07$)$ & $>0.05$ \\
FEV & & & & & \\
$\quad$ All & 37 & $3.67(0.66)$ & $3.99(0.54)$ & $-0.32(-0.47$ to -0.17$)$ & $<0.01$ \\
Smokers & 12 & $3.30(0.58)$ & $3.70(0.38)$ & $-0.40(-0.67$ to -0.12$)$ & $<0.01$ \\
$\quad$ Ex-smokers & 13 & $3.83(0.80)$ & $4.08(0.57)$ & $-0.26(-0.60$ to 0.09$)$ & $>0.05$ \\
$\quad$ Non-smokers & 12 & $3.87(0.43)$ & $4.19(0.54)$ & $-0.32(-0.53$ to -0.12$)$ & $<0.01$ \\
\hline
\end{tabular}

$\mathrm{FEV}_{1}=$ forced expiratory volume in one second.

Table 3 Lung function by occupational exposure to CoCrMo dust

\begin{tabular}{|c|c|c|c|c|c|}
\hline \multirow[t]{2}{*}{ Exposure } & \multirow[t]{2}{*}{ No. } & \multicolumn{2}{|l|}{ Vital capacity } & \multicolumn{2}{|l|}{$F E V_{1}$} \\
\hline & & Unadjusted difference $(95 \%$ CI) & Adjusted difference $(95 \% \mathrm{CI})$ & Unadjusted difference $(95 \% \mathrm{CI})$ & Adjusted difference $(95 \% \mathrm{CI})$ \\
\hline \multicolumn{6}{|c|}{$\begin{array}{l}\text { Hours/week of work with } \\
\text { CoCrMo }\end{array}$} \\
\hline $\begin{array}{l}\leqslant 9 \\
10-39 \\
40+\end{array}$ & $\begin{array}{l}12 \\
11 \\
14\end{array}$ & $\begin{array}{l}-0.08(-0.42 \text { to } 0.26) \\
-0.40(-0.76 \text { to }-0.04) \\
-0.50(-0.82 \text { to }-0.18)\end{array}$ & 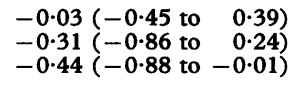 & $\begin{array}{l}-0.10(-0.34 \text { to } \\
-0.14) \\
-0.18(-0.42 \text { to } 0.07) \\
-0.61(-0.83 \text { to }-0.39)\end{array}$ & $\begin{array}{l}-0.09(-0.38 \text { to } 0.19) \\
-0.17(-0.54 \text { to } 0.21) \\
-0.61(-0.91 \text { to }-0.31)\end{array}$ \\
\hline \multicolumn{6}{|c|}{$\begin{array}{l}\text { Self estimated dust } \\
\text { exposure level }\end{array}$} \\
\hline $\begin{array}{l}\text { Low } \\
\text { Medium } \\
\text { High }\end{array}$ & $\begin{array}{l}11 \\
13 \\
13\end{array}$ & $\begin{array}{l}-0.21(-0.56 \text { to } 0.15) \\
-0.17(-0.49 \text { to } 0.16) \\
-0.62(-0.94 \text { to }-0.29)\end{array}$ & $\begin{array}{l}-0.18(-0.67 \text { to } 0.32) \\
-0.15(-0.54 \text { to } 0.25) \\
-0.57(-1.09 \text { to }-0.05)\end{array}$ & $\begin{array}{l}-0.17(-0.43 \text { to } 0.10) \\
-0.23(-0.48 \text { to } 0.02) \\
-0.53(-0.78 \text { to }-0.28)\end{array}$ & $\begin{array}{l}-0.23(-0.60 \text { to } 0.14) \\
-0.27(-0.57 \text { to } 0.03) \\
-0.59(-0.98 \text { to }-0.20)\end{array}$ \\
\hline
\end{tabular}

$\mathrm{FEV}_{1}=$ forced expiratory volume in one second.

Difference of observed to expected value (litres) analysed by multiple regression analysis, with and without adjustment for smoking. 
Table 4 Interobserver agreement of radiological findings by ILO category in dental technicians exposed to CoCrMo dust $(n=35)$ and controls $(n=21)$

\begin{tabular}{|c|c|c|c|c|c|}
\hline \multirow{2}{*}{$\begin{array}{l}\text { ILO category, } \\
\text { reader } A\end{array}$} & \multicolumn{4}{|c|}{ ILO category, reader $B$} & \multirow[b]{2}{*}{ Total } \\
\hline & 0 & 1 & 2 & 3 & \\
\hline 0 & 51 & 1 & 0 & 0 & 52 \\
\hline 1 & 1 & 3 & 0 & 0 & 4 \\
\hline 2 & 0 & 0 & 1 & 0 & 1 \\
\hline 3 & 0 & 0 & 0 & 0 & 0 \\
\hline Total & 52 & 4 & 1 & 0 & $57^{\mathrm{a}}$ \\
\hline
\end{tabular}

a Unweighted Cohen's kappa $=0 \cdot 78$.

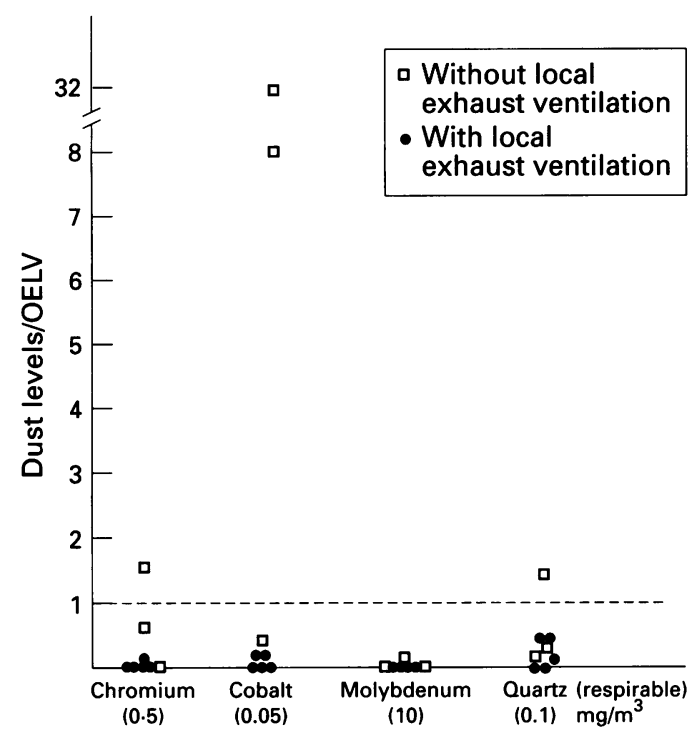

Dust levels in eight dental laboratories in relation to Swedish occupational exposure limit values (OELV,----), Absolute values given in parentheses. ${ }^{19}$

\section{ASSESSMENT OF EXPOSURE}

The contents of some historical dental material could not be ascertained, but they were believed to have been qualitatively equivalent to those identified. The principal components of the products used are shown in table 5 . Beryllium was not found in either contemporary or historical CoCrMo formulae available in Sweden.

With the use of local exhaust ventilation during grinding dust levels were generally very low, typically a few percent of the Swedish occupational exposure limit for the various components or even below the detection limit of the analytical method (figure). However, without adequate ventilation considerably higher dust levels could be recorded. For total cobalt dust a maximum value of $1.6 \mathrm{mg} / \mathrm{m}^{3}-$ that is, 32 times the Swedish occupational exposure limit for that particular metal - was found in one dental laboratory. At this par-

Table 5 Content of some dust-emitting products used in laboratories manufacturing CoCrMo dentures

\begin{tabular}{lll}
\hline Product & Material & Content (\%) \\
\hline CoCrMo alloys & Cobalt & $60-66$ \\
& Chromium & $25-32$ \\
& Molybdenum & $4-6$ \\
Grinding or polishing wheels & Other (e.g. silicone, manganese) & $<1$ \\
& Aluminium oxide & ND \\
& Silicon carbide & ND \\
Investment powders & Synthetic rubber & $80-99$ \\
Shot-blasting material & Crystalline quartz & $>99$ \\
\hline
\end{tabular}

$\mathrm{ND}=$ no data. ticular location the levels of total chromium and respirable silica dust both also exceeded the occupational exposure limit value by some $50 \%$. Cristobalite, tridymite, and silicon carbide levels were all below $0.02 \mathrm{mg} / \mathrm{m}^{3}$.

\section{Discussion}

The $16 \%$ prevalence of dental technician's pneumoconiosis in the study group (95\% confidence interval $6 \%$ to $23 \%$ ) should be regarded as representing a maximum estimate since the study population was restricted to include only technicians with a minimum of five years of exposure to CoCrMo dust. Conversely, this figure might also represent a survivor population but, since no cases of dental technician's pneumoconiosis were known in Sweden before the detection of the index case in 1985, this possibility cannot be fully evaluated. However, there are no good reasons to expect a substantial survivor effect. CoCrMo-based dental constructions were introduced in Sweden on a limited basis soon after World War II, but were used more extensively a decade later ( $P$ O Glantz, personal communication, 1993). Given a latency period of, say, 10 years for pneumoconiosis, cases of dental technician's pneumoconiosis might have appeared in the early 1960s. Indeed, in the nationwide survey of silicosis in the early 1970s high levels of silica dust were found in dental laboratories which produced CoCrMo dentures ${ }^{21}$ but no cases of pneumoconiosis were observed in these locations. Moreover, the production of CoCrMobased dental applications in Sweden mainly takes place in a limited number of specialised dental laboratories with few exposed subjects, and it is unlikely that we would have missed more than sporadic subjects fulfilling the inclusion criteria.

The occurrence of dental technican's pneumoconiosis in this study group is largely in agreement with findings in similar studies. For instance, with a minimum of 20 years of exposure to mechanical dentistry Rom et al ${ }^{10}$ reported a prevalence rate of simple pneumoconiosis (ILO profusion $1 / 0$ or more) of $16 \cdot 7 \%$. These subjects had worked extensively with non-precious alloys. Choudat et al ${ }^{13}$ found a prevalence of $15.8 \%$ for ILO profusion $1 / 0$ or more in subjects with at least 20 years of exposure (prevalence rate inferred from figure), whereas Sherson et $a l^{12}$ observed a $19 \cdot 4 \%$ prevalence of simple pneumoconiosis in 31 subjects where all cases had been exposed to CoCrMo dust in the production of dental prostheses. In contrast, no case of pneumoconiosis was observed among technicians not exposed to CoCrMo dust.

The decrease of $6 \%$ for VC and $8 \%$ for $\mathrm{FEV}_{1}$, respectively, in this study was more pronounced than in some of the other recent surveys in this field using a similar study design. This might be due to stricter inclusion criteria in our study group involving only dental technicians with a long exposure to potentially fibrogenic dust. Moreover, the impairment of lung function, after allowing for smoking habits, showed a dose-response relation with the intensity of the 
CoCrMo dust exposure in terms of the number of hours exposed per week and self-estimated exposure level. The absence of a negative trend for the number of years exposed was probably due to an inverse relation between the number of hours exposed per week and the number of years exposed. The reduction in ventilatory capacity could be interpreted as supporting the case observations of dental technician's pneumoconiosis and as being indicative of early lung fibrosis. However, the absence of a significant difference in lung function between cases of dental technician's pneumoconiosis and the remainder of the study group argues against this theory. Alternatively, the reduced lung function may indicate a component of bronchoconstriction representing a parallel phenomenon of cobalt-induced obstructive lung dysfunction. ${ }^{22}$

In the evaluation of the lung function data some factors which tend to exert a conservative influence on the outcome variables should be discussed. In particular, smoking habits were not taken into account in the reference material used to derive expected values. ${ }^{17}$ The proportion of smokers among Swedish men aged 30-64 years was considerably higher (approximately $75 \%$ ) in the mid $1950 \mathrm{~s}^{23}$ when the reference data were collected than the $32 \%$ noted in the present study. Accordingly, the reference data may be significantly influenced by smoking. This would tend to lower the expected values. Moreover, birth cohort effects - that is, new generations having better lung function than their ancestors ${ }^{24}$ - would be expected, given the time span in data collection of almost three decades between the present study group and the reference material.

The number of dust samples in this study was limited. However, all samples obtained from dental laboratories with local exhaust ventilation indicate that the occupational exposure limits were well contained. In contrast, in laboratories without such equipment high levels were found, particularly of cobalt. In this respect our results are in accordance with those of Brune and Beltesbrekke ${ }^{25}$ who found cobalt levels of $1.0-1.2 \mathrm{mg} / \mathrm{m}^{3}$ in laboratories where exhaust ventilation was not used and $<0.1 \mathrm{mg} /$ $\mathrm{m}^{3}$ with ventilation.

In conclusion, reduced lung function and pneumoconiosis are hazards which face dental technicians exposed to dust generated in the processing of CoCrMo alloys. For prevention, local exhaust ventilation should be encouraged.
The authors would like to acknowledge Inga Andersson for the medical field work, Hảkan Arvidsson and Gunnar Hillerdal for reviewing the chest radiogrder ing Liss Bryngelsson for their assistance with the data processing, Margaretha Sandin for producing the manuscript, and Olav Axelson for his useful comments. This study was supported by the Swedish Work Environment Fund, Contract 88-0601.

1 Silzbach LE. The silicosis hazard in mechanical dentistry. ҰAMA 1939;113:1116-9.

2 Ahlmark A, Bruce T, Nyström Å. Silicosis and other pneumoconioses in Sweden. Stockholm: Svenska Bokförlaget, 1960:311-2.

3 Willard JJ, Personne C. Note médicale concernant une silicose nodulaire. Eur F Toxicol 1969;2:79-82.

4 Beck B, Irmscher G. Silikosen durch weniger bekannte Expositionsarten. $Z$ Erkr Atm 1974;140:282-93.

5 Briotet A, Le Magrex L, Parant C, Potevin C, Seitz B, Signouret $M$, et al. Les risques de silicose chez les prothésistes dentaires. Arch Mal Prof Med 1979;40:122-3.

6 Hansen HM. Silikose hos en tandtekniker. Ugeskr Laeger 1983;145:2378-9.

7 Hugonnaud C, Lob M. Risques encourus par les techniciens-dentistes lors de l'usinage de prothèses métalliques. Soz Präventivmed 1976;21:139.

8 Carles P, Fabre J, Pujol M, Duprez A, Bollinelli R. Pneumoconioses complexes chez les prothésistes dentaires. Poumon Coeur 1978;34:189-92.

9 von Kronenberger $H$, Morgenroth $K$, Tuengerthal S, Schneider M, Meier-Sydow J, Riemann H, et al. Pneumokoniosen bei einem Zahntechnikerkollektiv. Atemwegs Lungenkrankh 1980;6:279-82.

10 Rom WN, Lockey JE, Lee JS, Kimball AC, Moon Bang K, Leaman $\mathrm{H}$, et al. Pneumoconiosis and exposures of dental laboratory technicians. Am ₹ Publ Health 1984;74:1252-7.

11 de Vuyst $P$, Vande Weyer R, de Coster A, Marchandise FX, Dumortier P, Ketelbant $\mathrm{P}$, et al. Dental technician's pneumoconiosis. A report of two cases. Am Rev Respir Dis 1986;133:316-20.

12 Sherson D, Maltbaek N, Olsen O. Small opacities among dental laboratory technicians in Copenhagen. $\mathrm{Br} F$ Ind Med 1988;45:320-4.

13 Choudat D, Triem S, Weill B, Vicrey C, Ameille J, Brochard $\mathrm{P}$, et al. Respiratory symptoms, lung function, and pneumoconiosis among self employed dental technicians. pr f Ind Med 1993;50:443-9.

14 Persson B, Brune D. Dental laboratories. In: Brune DK, Edling C, eds. Occupational hazards in the health professions. Boca Raton: CRC Press, 1989;333-45.

15 Andersson I, Bornberger S, Persson B, Ákerstedt K. Tandteknikerprojektet 1982-1983 (in Swedish). Tandteknikern 1984;53:92-132.

16 Ydreborg B. Questionnaire-based database on occupation and health status. Inf Serv Use 1990;10:46-51.

17 Berglund E, Birath G, Bjure J, Grimby G, Kjellmer I Sandqvist $L$, et al. Spirometric studies in normal subjects. I. Forced expirograms in subjects between 7 and 70 years I. Forced expirograms in subjects between
of age. Acta Med Scand 1963;173:185-91.

18 International Labour Office guidelines for the use of the ILO international classification of radiographs of pneumoconioses. International Labour Office Occupational Safety and Health Series No 22. Geneva: ILO, 1980.

19 Arbetarskyddsstyrelsen. Hygieniska gränsvänden. Stockholm: Arbetarskyddsstyrelsens fơrfattningssamling, 1987:12 (in Swedish).

20 Fleiss JL. Statistical methods for rates and proportions. New York: John Wiley \& Sons, 1981:212-25.

21 Gerhardsson G, Engman L, Andersson A, Isaksson G, Magnusson E, Sundqvist S. Tandtekniska laboratorier. Silikosprojektets slutrapport. Del 2. Madsättning, omfattning och likosprojektets slutrapport. Del 2. Mälsättning, omfattning och
resultat. Undersökningsrapport AMT 103/74-2. Stockresultat. Undersőkningsrapport AMT 103/74-2. Stock-

22 Balmes JR. Respiratory effects of hard-metal dust exposure. Occup Med State Art Rev 1987;2:327-44.

23 Socialstyrelsen. Socialstyrelsen redovisar 1986:9. Stockholm: Socialstyrelsen, 1986:127 (in Swedish)

24 Glindmeyer HW, Diem JE, Jones RN, Weill H. Noncomparability of longitudinally and cross-sectionally determined annual change in spirometry. Am Rev Respir Dis termined annual cha

25 Brune D, Beltesbrekke H. Dust in dental laboratories. Part I. Types and levels in specific operations. $\mathcal{F}$ Prosthet Dent 1980;43:687-92. 